\title{
Review Article \\ Pentraxin 3 as a Prognostic Biomarker in Patients with Systemic Inflammation or Infection
}

\author{
Siguan Liu, ${ }^{1,2}$ Xin Qu, ${ }^{1,3}$ Feng Liu, ${ }^{4}$ and Chunting Wang ${ }^{1}$ \\ ${ }^{1}$ Department of Critical Care Medicine, Provincial Hospital Affiliated to Shandong University, Jinan 250021, China \\ ${ }^{2}$ Department of Emergency, Zaozhuang Municipal Hospital, Zaozhuang, Shandong 277101, China \\ ${ }^{3}$ Department of Critical Care Medicine, Beijing Tiantan Hospital, Capital Medical University, Beijing 100050, China \\ ${ }^{4}$ Department of Internal Medicine, Rongcheng Traditional Hospital, Weihai 264300, China
}

Correspondence should be addressed to Chunting Wang; chuntingwangicu@126.com

Received 4 August 2014; Accepted 7 October 2014; Published 3 November 2014

Academic Editor: Vinod K. Mishra

Copyright ( 2014 Siguan Liu et al. This is an open access article distributed under the Creative Commons Attribution License, which permits unrestricted use, distribution, and reproduction in any medium, provided the original work is properly cited.

\begin{abstract}
Purpose. The long pentraxin 3 (PTX3) is a key component of the humoral arm of the innate immune system. PTX3 is produced locally in response to proinflammatory stimuli. We reviewed the usefulness of systemic levels of PTX3 in critically ill patients with systemic inflammatory response syndrome (SIRS), sepsis, and bacteremia, focusing on its diagnostic and prognostic value. Methods. A PubMed search on PTX3 was conducted. The list of papers was narrowed to original studies of critically ill patients. Eleven papers on original studies of critically ill patients that report on PTX3 in SIRS, sepsis, or bacteremia were identified. Results. Systematic levels of PTX3 have little diagnostic value in critically ill patients with SIRS, sepsis, or bacteremia. Systemic levels of PTX3, however, have superior prognostic power over other commonly used biological markers in these patients. Systemic levels of PTX3 correlate positively with markers of organ dysfunction and severity-of-disease classification system scores. Finally, systemic levels of PTX3 remain elevated in the acute phase and decreased on recovery. Notably, the age of the patients and underlying disease affect systemic levels of PTX3. Conclusions. The diagnostic value of PTX3 is low in patients with sepsis. Systemic levels of PTX3 have prognostic value and may add to prognostication of patients with SIRS or sepsis, complementing severity-of-disease classification systems and other biological markers.
\end{abstract}

\section{Introduction}

Pentraxin 3 is a secretory protein classified as a long pentraxin subfamily member of the pentraxin family. The pentraxin family proteins, which are evolutionarily conserved multimeric pattern recognition receptors and share a pentraxinlike domain in the $\mathrm{C}$ terminus, are recognized as key components of humoral innate immunity [1]. PTX3 has a unique 200 -amino acid domain in its $\mathrm{N}$ terminus and is known to play multiple roles, including the regulation of inflammatory reaction, innate resistance to pathogens, and female fertility [2]. PTX3 is expressed in a variety of cells at inflammatory sites [3] and is also stored in neutrophil-specific granules [4]. As the pentraxin C-reactive protein (CRP) and serum amyloid $\mathrm{P}$ component (SAP) are well-known acute phase proteins, PTX3 may also be an acute phase biomarker. Recently, many studies on the circulating PTX3 level in clinical trials have been reported. These reports indicate that the PTX3 levels are significantly increased in tuberculosis, cardiovascular, kidney, and female reproductive system diseases, as well as severe traumatic brain injury [5-10]. In addition, systemic levels of PTX3 have been shown to have prognostic value in predicting the severity and outcome in patients with cancer $[11,12]$. Elevated plasma levels of PTX3 were also found to have a strong prognostic value in dengue virus infection [13] and leptospirosis [14].

Systemic levels of PTX3 are also increased in critically ill patients [15]. However, the usefulness of PTX3 as a biological marker in critical illness is uncertain. The aim of this systematic review is to provide an overview of studies investigating the diagnostic and prognostic properties of PTX3 in critically ill patients with SIRS, sepsis, or bacteremia. We hypothesized that PTX3 has both diagnostic and prognostic values in these inflammatory conditions. We also hypothesized that systemic 
concentrations of PTX3 correlate with severity-of-disease classification system scores and other biological markers of severity of disease. Finally, we were interested in changes in systemic levels of PTX3 after initiation of treatment to observe whether PTX3 has any potential in guiding therapy.

\section{Materials and Methods}

2.1. Data Sources. Two methods were used to identify relevant papers on PTX3 as a biological marker in critically ill patients in the medical literature. First, an electronic search in the PubMed database was performed. Searches were also performed using the Cochrane Library and the Cochrane Database of Systematic reviews. Second, reference lists of identified and selected papers were reviewed for studies not identified with our search. Searches were restricted to original studies in humans and written in English.

2.2. Keywords (Text Word). The following keywords were used, alone or in combination, to identity relevant papers: (1) condition "critical care" or "intensive care", (2) subject "human", (3) test "pentraxin 3" or "PTX3" or "soluble pentraxin 3 receptor" or "soluble PTX3" or "soluble PTX3 receptor" or "Tumor necrosis factor-stimulated gene 14" or "Tumor necrosis factor-stimulated gene 14 receptor" or "TSG-14", and (4) disease "systemic inflammatory response syndrome," "sepsis," "septic shock," or "bacteremia".

2.3. Study Selection. Titles and abstracts were reviewed, and papers that reported on studies of PTX3 in critically ill patients with systemic inflammation or infection were selected. Thus, only papers on studies of critically ill patients were included (i.e., studies of patients who were admitted to a hospital with systemic inflammation or infection or to an intensive care unit (ICU)). In case of uncertainty, the complete paper was obtained and evaluated. Inclusion of papers was not restricted by methodological quality or any other critically appraisal criteria other than the criteria formulated for data extraction.

2.4. Quality Assessment. The quality of the included studies was evaluated by applying the 25 -item criteria developed by the Standards for Reporting of Diagnostic Accuracy (STARD) committee $[16,17]$. The maximum quality score that could be given to a study was 25 points over five categories. For each category, results were derived from consensus among all reviewers.

2.5. Data Extraction. Manuscripts were criticized along the following four subjects: (1) PTX3 is a useful diagnostic marker in detection of infection, (2) PTX3 is a useful prognostic marker in patients with SIRS, sepsis, or bacteremia, (3) systemic concentrations of PTX3 correlate with disease severity scores and markers of organ failure in these patients, and (4) how do systemic levels of PTX3 respond to initiation of treatment?

\section{Results}

3.1. Search Results. The search performed in April 2014 in the PubMed database revealed eleven papers as original studies [15, 18-27]. The Cochrane Library and the Cochrane Database of Systematic reviews revealed no reviews or metaanalyses of PTX3 in patients. Quality evaluation of the included studies using the STARD checklist is presented in Table 1.

Study populations in the retrieved studies comprised patients with SIRS, sepsis and/or septic shock, and bacteremia. Importantly, definitions for diagnoses varied among the studies. Table 2 presents the criteria used for diagnosis of each study.

Seven studies evaluated the diagnostic value of PTX3 [15, 19, 21-26]; eleven studies investigated the prognostic value of PTX3 [15, 18-27]. Six studies correlated systemic levels of PTX3 to disease severity scores [15, 18, 20, 22, 24, 27]; four studies investigated changes of systemic levels of PTX3 after initiation of treatment [20-22, 27].

3.2. Diagnostic Value of PTX3. Systemic levels of PTX3 were significantly higher in critically ill patients, compared to healthy controls [15, 20,21, 24, 27]. Higher levels of PTX3 were associated with the development of sepsis, severe sepsis, and septic shock [15, 18, 20, 21, 24-26]. Moreover, the area under the curve (AUC) of 0.922 (cut-off value $16.0 \mathrm{ng} / \mathrm{mL}$, sensitivity $89.1 \%$, and specificity $85 \%$ ) to discriminate between healthy controls and SIRS was found [24]. Also, in patients with suspected infection admitted to the emergency room, the AUC for prediction of severe sepsis between day 0 and day 28 was 0.73 for PTX3 (cut-off value $14.1 \mathrm{ng} / \mathrm{m}$, sensitivity $63 \%$, specificity $80 \%$ ) [25]. However, in patients who fulfilled at least two criteria for SIRS, using Dunn's posttest, it was revealed that only the SIRS group differed significantly from the other groups, while no significant difference was observed between the sepsis, severe sepsis, and septic shock groups.

Systemic levels of PTX3 were significantly higher in patients with blood culture-positive bacteremia compared to healthy controls [21] and blood culture negative samples $[18,24]$. High levels of PTX3 were associated bacteremia $[21,23]$. In febrile patients at the emergency department, the AUC in the prediction of bloodstream infection was 0.71 , at a cut-off level for $16.1 \mathrm{ng} / \mathrm{mL}$ with $76 \%$ sensitivity and $61 \%$ specificity [21]. Finally, the PTX3 threshold of $>16.43 \mathrm{ng} / \mathrm{mL}$ provided a specificity of $74.0 \%$ and a sensitivity of $68.6 \%$ for the diagnosis of ventilator-associated pneumonia (VAP) [26].

However, levels of PTX3 in patients with gram-positive bacteremia did not appear to be different from those with gram-negative bacteremia [21]. Also, the values did not differ significantly between patients with infection caused by different culprit organisms (i.e., Staphylococcus aureus, Streptococcus pneumoniae, $\beta$-hemolytic Streptococcaceae, and Escherichia coli) [22]. But levels of PTX3 have been shown to be the highest in patients with urinary tract infections than in those with pulmonary infections and abdominal infection and other infections [20].

PTX3 values showed a positive correlation with other frequently used biological markers that can be measured 


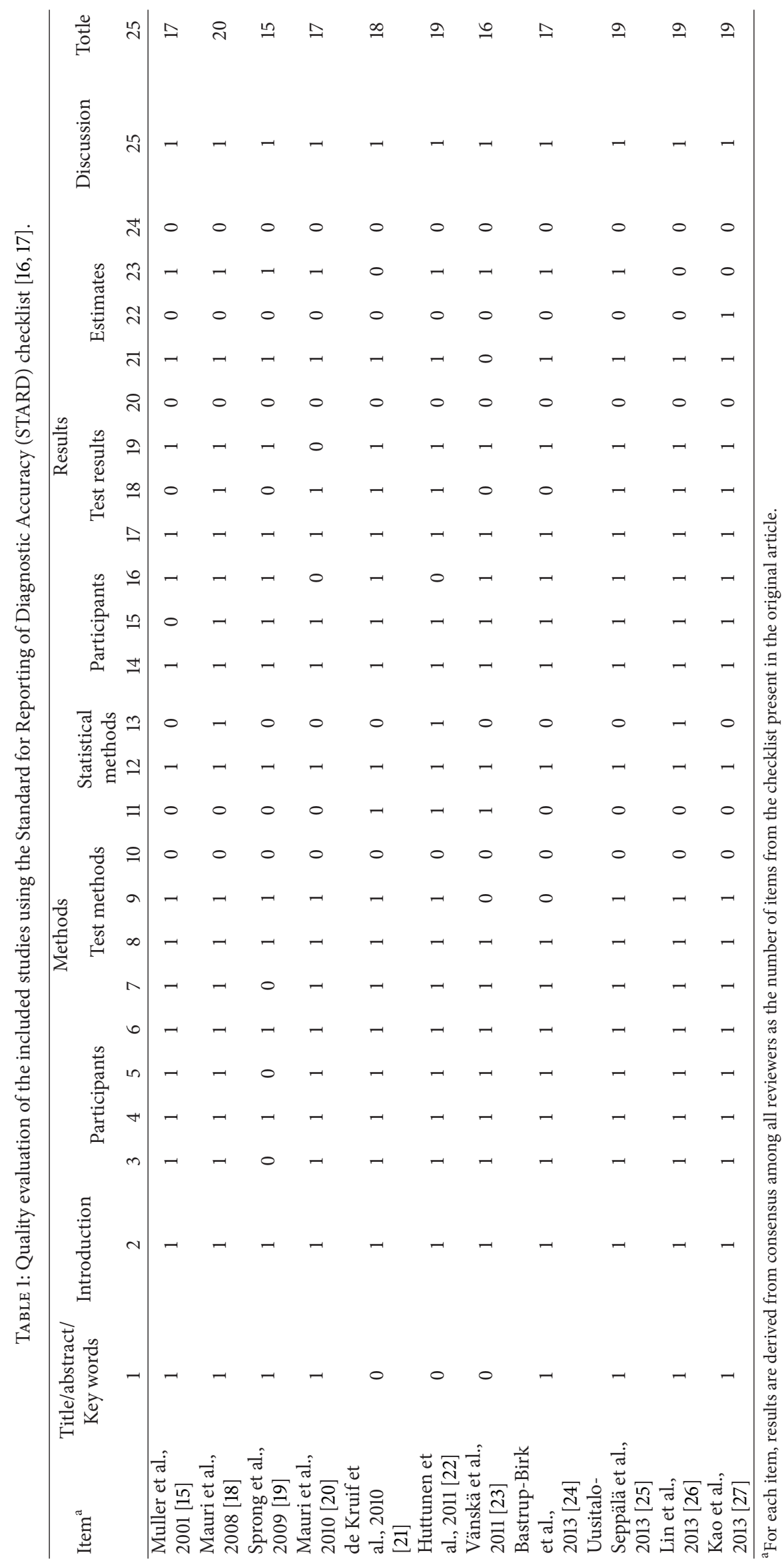


TABLE 2: Patients characteristics of the included studies.

\begin{tabular}{|c|c|c|c|c|}
\hline First author & References & Criteria used for diagnosis & $\begin{array}{l}\text { Diagnosis on admission as } \\
\text { described by the authors } \\
\text { (no. of patients) }\end{array}$ & Period \\
\hline Muller & {$[15]$} & $\begin{array}{l}\text { SIRS, sepsis, severe sepsis, and } \\
\text { septic shock criteria }\end{array}$ & $\begin{array}{l}\text { Sepsis, severe sepsis, or septic shock } \\
\text { (33) SIRS (68) }\end{array}$ & September 1996 to June 1997 \\
\hline Mauri & {$[18]$} & $\begin{array}{l}\text { ALI/ARDS criteria } \\
\text { SIRS, septic, severely septic or } \\
\text { septic shock criteria }\end{array}$ & $\begin{array}{l}\text { ALI/ARDS (21) } \\
\text { Nonseptic (3), SIRS (4), septic (0), } \\
\text { severely septic (5), septic shock (9) }\end{array}$ & January 2005 to October 2006 \\
\hline Sprong & [19] & Meningococcal disease & meningococcal disease (26) & 1994 to 2004 \\
\hline Mauri & {$[20]$} & $\begin{array}{l}\text { Severe sepsis or septic shock } \\
\text { criteria }\end{array}$ & Severe sepsis (18), septic shock (72) & December 2004 to March 2007 \\
\hline de Kruif & {$[21]$} & Fever criteria, bacteremia criteria & $\begin{array}{l}\text { Febrile patients (211), bacteremia } \\
\text { (35) }\end{array}$ & $\begin{array}{l}\text { April } 2004 \text { to October 2006, one } \\
\text { month follow-up after } \\
\text { enrollment }\end{array}$ \\
\hline Huttunen & {$[22]$} & $\begin{array}{l}\text { Blood culture positive for } \\
\text { S. aureus, } S \text {. pneumoniae, } \\
\beta \text {-hemolytic Streptococcus or } \\
\text { E. coli }\end{array}$ & Bacteremia (132) & June 1999 to February 2004 \\
\hline Vänskä & {$[23]$} & $\begin{array}{l}\text { Neutropenic fever and septic } \\
\text { chock criteria }\end{array}$ & $\begin{array}{l}\text { Neutropenic fever (100), septic } \\
\text { shock (5) }\end{array}$ & $\begin{array}{l}\text { December } 2006 \text { to December } \\
2009\end{array}$ \\
\hline Bastrup-Birk & {$[24]$} & SIRS criteria & SIRS (261) & $\begin{array}{l}\text { Undefined, median follow up } \\
\text { time } 873 \text { (range, 0-1458) days }\end{array}$ \\
\hline Uusitalo-Seppälä & {$[25]$} & $\begin{array}{l}\text { Suspected infection : Bacterial } \\
\text { infection, SIRS, Sepsis and Severe } \\
\text { sepsis criteria }\end{array}$ & $\begin{array}{l}\text { Suspected infection (537): Bacterial } \\
\text { infection (67), SIRS (54), Sepsis } \\
(308) \text {, severe sepsis (49) }\end{array}$ & $\begin{array}{l}2004 \text { to } 2005,14 \text { months, one } \\
\text { year } \\
\text { follow-up after enrollment }\end{array}$ \\
\hline Lin & {$[26]$} & VAP criteria & VAP (86) & $\begin{array}{l}\text { January } 2010 \text { to December 2011, } \\
28 \text { days follow-up after } \\
\text { enrollment }\end{array}$ \\
\hline Kao & {$[27]$} & CAP criteria & CAP (61) & January 2009 to December 2009 \\
\hline
\end{tabular}

easily with commercially available kits, including CRP, IL6, procalcitonin (PCT), and calcitonin precursors (CTpr) $[15,24,25]$. In the case of sepsis patients, both PTX3 and high PCT seemed to be independent predictors of severe sepsis while CRP did not [25]. But the study of patients with SIRS showed that PTX3 and CRP had similar performance in discriminating between SIRS and sepsis [24]. However, in critically ill patients, PTX3 was no better than CTpr as a diagnostic index of infection and sepsis [15].

3.3. Prognostic Value of PTX3. Systemic levels of PTX3 were significantly high in critically ill patients with fatal outcomes compared to patients who survived critical illness $[15,18,20$, 23-26]. In patients with bacteremia, the maximum PTX3 values on days 1-4 were markedly higher in nonsurvivors compared to survivors ( 44.8 versus $6.4 \mathrm{ng} / \mathrm{mL}, P<0.001$ ) and the AUC in the prediction of case fatality was 0.82 (cut-off values $15 \mathrm{ng} / \mathrm{mL}$, sensitivity $72 \%$, and specificity $81 \%$ ) [22]. Similarly, the AUC in emergency room patients with suspected infection was 0.69 (cut-off value $7.7 \mathrm{ng} / \mathrm{mL}$, sensitivity $70 \%$, specificity $63 \%$ ) in predicting case fatality on day 28 [25]. Of note, the rate of positive blood cultures was $8.3 \%$ and case fatality by day 28 after admission $6.7 \%$. In addition, SIRS patients with high levels of PTX3 at admission did have a higher 90day mortality rate than patients with the $25 \%$ lowest levels
(Cox regression analysis; hazard ratio 3.0; $P=0.0009$ ) [24]. In patients with severe sepsis or septic shock, a value of day 5: day 1 PTX3 of 0.76 predicted death with $64 \%$ specificity and $72 \%$ sensitivity (positive likelihood ratio 1.98). Every 0.01 increase in day 5 : day 1 PTX3 levels increased the probability of death by 3.7\% (95\% confidence interval 1.2-6.3\%) [20].

As a single biological marker, PTX3 was superior in predicting mortality compared to other frequently used biological markers, including CRP, IL-6, and TNF- $\alpha$ (Table 3 ) $[15,18$, $20,22-26]$. The ability of PTX3 to predict mortality was poor compared to the conventional simplified acute physiology score (SAPS) II [15].

3.4. Correlation of PTX3 with the Severity of Disease. In patients with suspected infection, a high PTX3 level ( $\geq 14.1 \mathrm{ng} /$ $\mathrm{mL}$; optimal cut-off value for severe sepsis) was associated with several endpoints reflecting the severity of the disease (need for ICU stay, hypotension, and acute renal insufficiency) [25]. Similar associations were described for blood culture-positive bacteremic patients [22]. In patients with meningococcal disease, high PTX3 and low CRP concentration at admission discriminated between presence and absence of shock [19]. In patients with community-acquired pneumonia (CAP), the plasma concentration of PTX3, but not CRP, was correlated with the severity of CAP based 
TABle 3: Prognostic value of PTX3 to predict mortality as compared to other biological markers and disease severity scores.

\begin{tabular}{|c|c|c|c|c|c|c|}
\hline Ability to predict & Parameter & AUC $(95 \% \mathrm{CI})$ & Cutoff & Sensitivity (\%) & Specificity (\%) & References \\
\hline \multicolumn{7}{|c|}{ General intensive care unit population } \\
\hline \multirow{5}{*}{ ICU mortality } & PTX3 & 0.63 & - & - & - & \multirow{5}{*}[15]{} \\
\hline & IL-6 & 0.72 & - & - & - & \\
\hline & CRP & 0.55 & - & - & - & \\
\hline & CTpr & 0.61 & - & - & - & \\
\hline & SAPSII & 0.76 & - & - & - & \\
\hline \multirow{4}{*}{ 90-Day mortality } & PTX3 (day 5 : day 1 ) & 0.73 & 0.76 & 64 & 72 & \multirow{4}{*}[20]{} \\
\hline & CRP (day $5:$ day 1$)$ & 0.58 & - & - & - & \\
\hline & IL-6 (day 5 : day 1 ) & 0.63 & - & - & - & \\
\hline & IF- $\alpha$ (day $5:$ day 1$)$ & 0.61 & - & - & - & \\
\hline \multicolumn{7}{|c|}{ Patients with infectious diseases } \\
\hline \multirow{3}{*}{ 28-Day mortality } & PTX3 & 0.69 (CI 0.58-0.79) & $7.7 \mathrm{ng} / \mathrm{mL}$ & 70 & 63 & \multirow{3}{*}[25]{} \\
\hline & PCT & $0.65(\mathrm{CI} 0.57-0.74)$ & $0.19 \mathrm{ng} / \mathrm{mL}$ & 82 & 63 & \\
\hline & CRP & 0.50 (CI $0.38-0.62)$ & - & - & - & \\
\hline \multicolumn{7}{|c|}{ Bacteremic patients } \\
\hline \multirow[t]{2}{*}{ 30-Day mortality } & $\begin{array}{l}\text { PTX3 (the maximum value } \\
\text { on days } 1 \text { to } 4 \text { ) }\end{array}$ & 0.82 (CI 0.73-0.91) & $15 \mathrm{ng} / \mathrm{mL}$ & 72 & 81 & \multirow{2}{*}[22]{} \\
\hline & $\begin{array}{l}\text { CRP (the maximum value } \\
\text { on days } 1 \text { to } 4 \text { ) }\end{array}$ & 0.61 (CI 0.49-0.73) & - & - & - & \\
\hline \multirow{3}{*}{ 28-Day mortality } & PTX3 & $0.781 \pm 0.065$ & $>44.45 \mathrm{ng} / \mathrm{mL}$ & 64.7 & 88.4 & \multirow{3}{*}[26]{} \\
\hline & CRP & $0.635 \pm 0.071$ & $>135.7$ & 64.7 & 62.3 & \\
\hline & PTX3 + CRP & $0.863 \pm 0.041$ & - & - & - & \\
\hline
\end{tabular}

on the pneumonia severity index (PSI), CURB-65, Acute Physiology and Chronic Health Evaluation (APACHE) II scores, and the length of hospital stay [27].

In critically ill patients admitted to the medical ICU, systemic levels of PTX3 also correlated with disease severity, as assessed by the APACHE II and SAPS II scores or sequential organ failure assessment (SOFA) score [15, 18, 20, 24]. PTX3 levels were shown to better correlate with severity of the disease and organ dysfunctions than other measured mediators (i.e., TNF $\alpha$, IL-6, and CRP) [20]. Of note, in patients with severe sepsis or septic shock, Dayl PTX3 was correlated with platelet count and prothrombin fragments $1+2$ concentration and with plasminogen activator inhibitor-1 (PAI-1) activity and concentration [20]. Moreover, in patients admitted to the intensive-/medium care unit, the levels of PTX3 were high in comparison to levels of patients referred to the ward. PTX3 was associated with duration of hospital stay and acute congestive heart failure [21].

3.5. Systemic Levels of PTX3 after Initiation of Treatment. Six studies evaluated levels of PTX3 after the initiation of treatment $[15,18,20-22,27]$. Systemic levels of PTX3 remained peaked during the first hours after hospital admission and were high in the acute phase and decreased after antibiotic treatment $[18,22,27]$. At admission, levels of PTX3 in febrile patients were significantly elevated in comparison to samples collected after full recovery at a one-month follow-up visit and correlated with the total duration of antibiotic treatment [21]. PTX3 remained elevated in the presence of unremitting disease [15]. PTX3 levels did not differ between the tight glycemic control strategy and conventional glycemic control strategy group for the first 5 days from enrollment $(P=0.221)$ [20].

3.6. Factors That Influence Levels of PTX3 and/or Its Performance. Some studies showed that age of patients and underlying diseases affected levels of PTX3 and/or its performance. Studies that investigated systemic levels of PTX3 in relation to age are contradictory [22-25]. Two studies found no correlation between systemic levels of PTX 3 on day 0 and age, sex, or comorbidities [22, 23]. However, two other studies suggested higher levels of PTX3 in elderly patients [24, 25]. In patients with bacteremia, levels of PTX3 were high in patients with chronic alcohol abuse compared to patients without a history of alcohol abuse, while there was no difference between groups of patients stratified by other chronic conditions, age, sex, or causative organism [22]. Interestingly, serum concentrations of PTX3 did not differ between sexes nor by whether the patients were admitted with a surgical or nonsurgical diagnosis [24]. PTX3 values were significantly high in patients with obesity (body mass index $(\mathrm{BMI}) \geq 30$ ), cardiovascular diseases, and continuous systemic cortisone treatment (daily dose over $10 \mathrm{mg}$ oral prednisolone) compared to those without these risk factors [25].

In one study, highly specific monoclonal antibodies against human PTX3 were produced and used to develop the new sandwich ELISA system. With this, PTX3 was detectable in serum at concentrations down to $0.3 \mathrm{ng} / \mathrm{mL}$. Moreover, 
the established assay was very stable and capable of measuring PTX3 exposed to consecutive freezing thawing cycles. In addition, a strength of this new assay was the very high correlation with a commercially available PTX3 assay (rho $0.8, P<0.001)[24]$.

\section{Discussion}

This systematic review shows that although systemic levels of PTX3 are elevated in more severe forms of sepsis and bacteremia, its diagnostic value is low, as PTX3 is a nonspecific marker of inflammation. Systemic levels of PTX3, however, do have prognostic value, with higher levels being associated with poor outcome. Systemic levels of PTX3 correlate positively with severity-of-disease classification scores and peaked earlier than CRP. Systemic levels of PTX3 also correlate positively with several markers of organ dysfunction.

The mortality rate of SIRS, sepsis, severe sepsis, and septic shock is high, ranging from approximately $10 \%$ in SIRS to $60 \%$ in septic shock [28]. While identification and treatment of sepsis has led to a decrease in mortality, the incidence continues to increase resulting in a still larger number of deaths annually [29]. Worldwide, sepsis is thus the major cause of death in intensive care units and therefore an area of concern [30]. In order to improve the survival of patients with SIRS and sepsis, it is essential to identify the individuals at high risk. One approach for this identification is constantly evaluating reliable biological markers. Traditional markers such as white blood cell count, fever, and CRP levels are not reliable for assessing disease severity and mortality risk $[31,32]$. Procalcitonin seems to be an improvement on these markers, but is not ideal [33-35]. Although PCT has repeatedly shown prognostic value in critically ill patients, the value of a single level on admission is limited [36]. The compiled data in this paper suggest that PTX3 has superior prognostic value compared to commonly used biological markers, including CRP. Moreover, PTX3 levels were high in the acute phase and reached the maximal point earlier than CRP. PTX3 may be used as an early biomarker in sepsis patients.

Pentraxin 3 is the prototype of the long pentraxin family $[37,38]$. It differs from CRP in terms of gene organization and localization, ligand recognition, producing cells, and inducing signals [39-41]. CRP is produced in the liver, whereas PTX3 is an inflammatory mediator produced by various cells in peripheral tissues. PTX3 values in healthy subjects are low (i.e., $<2 \mathrm{ng} / \mathrm{mL}$ ). PTX3 can be rapidly produced and released by mononuclear phagocytes, neutrophils, fibroblasts, and epithelial and endothelial cells in response to primary inflammatory signals (e.g., IL-1 and TNF- $\alpha$ ) [42]. It plays an important role in the early phase of inflammation: it recognizes microbial moieties, activates the classical pathway of complement, and facilitates recognition by macrophages and dendritic cells [43]. PTX3 has an important role in regulating the innate immune response by contributing to the opsonization and clearance of apoptotic or necrotic cells [44].

Although PTX3 alone was not performed as well as the SAPS II score, this does not necessarily preclude its use in prognostication. APACHE II score, SAPS II, SOFA score, and other scoring systems estimating the risk of mortality have become increasingly popular in the field of research with critically ill patients over the last decades. However, in clinical practice, these scoring systems have important limitations. Data collection requires multiple laboratory measurements and the computation of multiple variables and is labor intensive and expensive [45-47]. Therefore, the application of these scoring systems may be limited, particularly when health care is subject to financial constraint. PTX3 may have other important advantages. Only one blood sample instead of multiple clinical and laboratory measurements are needed. Measurement of PTX3 can be performed using a simple ELISA. In addition, PTX3 is stable in plasma samples subjected to repeated freeze-thaw procedures [24], increasing its practicality as a practical biological marker. Thus, based on the findings that systemic levels of PTX3 are a strong and robust marker of mortality risk, one could speculate that PTX3 will eventually serve as a quick, technically simple, and inexpensive alternative to the current sophisticated severityof-disease classification systems. Future studies are needed to address this hypothesis.

Notably, systemic levels of PTX3 remain elevated in the acute phase and decreased on recovery. Therefore, the use of PTX3 as a biological marker for guiding therapy is possible. However, studies addressing this issue are lacking. Importantly, the type of assay used to measure PTX3 and age and presence or absence of underlying diseases all influence PTX3 levels. The difference performance between different assays can be explained by the fact that the new sandwich ELISA assay uses highly specific monoclonal antibodies [24]. With the prognostic value of PTX3 in combination with other markers, this might compensate for the slightly impaired performance.

The finding that age as well as underlying disease influences the systemic level of PTX3 is of limited relevance as both age and underlying diseases are known to increase mortality risk in critically ill patients $[48,49]$. Systemic levels of PTX3 remained independently prognostic for mortality after adjusting for age and/or underlying diseases [20, 25-27]. As with other markers, such as CRP and PCT, experience will eventually dictate the value of PTX3 levels in diverse clinical situations.

Of interest, PTX3 is not only present in human plasma or serum but can also be found in other body fluids, including urine [50, 51], cerebrospinal fluid [52], pleural [53, 54], amniotic fluid [55], and joint fluid [56,57]. The number of studies investigating the value of PTX3 in body fluids other than plasma or serum, however, is very limited. It would be interesting to evaluate the value of local levels of PTX3 in other body fluids, that is, in bronchoalveolar lavage fluid of patients with frequent pulmonary complications, such as acute lung injury [18].

Finally, this review has limitations. The most common limitation of any systematic review is publication bias. Unpublished materials were not found and thus not used. However, the results from these relatively small studies need to be further validated in larger, multicenter trials before this approach can be recommended. Moreover, the heterogeneous nature of the current studies prevents any 
meta-analytic technique to derive an optimal range of values for prognostication.

\section{Conclusions}

The studies that have evaluated PTX3 levels vary in the types of patient populations studied, the basal conditions of the patients, and the methods used to measure PTX3. PTX3 in diagnosing sepsis does not appear to be superior to other biomarkers, like CRP and PCT. PTX3 seems a promising prognostic marker in critically ill patients. Currently, studies are limited to the predictive potential to estimate the mortality risk in observational designs. The monitoring of PTX3 levels during therapy needs further study to determine whether this biomarker could be of use in guiding therapeutic decisions.

\section{Conflict of Interests}

The authors declare that they have no conflict of interests.

\section{Authors' Contribution}

Siguan Liu and Xin Qu contributed equally to this work.

\section{Acknowledgments}

This work was supported by grants from the National Natural Science Foundation of China (no. 81372473) and China Postdoctoral Science Foundation (no. 2014M550766).

\section{References}

[1] B. Bottazzi, A. Doni, C. Garlanda, and A. Mantovani, "An integrated view of humoral innate immunity: pentraxins as a paradigm," Annual Review of Immunology, vol. 28, pp. 157-183, 2010.

[2] A. Mantovani, C. Garlanda, A. Doni, and B. Bottazzi, "Pentraxins in innate immunity: from $\mathrm{C}$-reactive protein to the long pentraxin PTX3," Journal of Clinical Immunology, vol. 28, no. 1, pp. 1-13, 2008.

[3] C. Garlanda, B. Bottazzi, A. Bastone, and A. Mantovani, "Pentraxins at the crossroads between innate immunity, inflammation, matrix deposition, and female fertility," Annual Review of Immunology, vol. 23, pp. 337-366, 2005.

[4] S. Jaillon, G. Peri, Y. Delneste et al., "The humoral pattern recognition receptor PTX3 is stored in neutrophil granules and localizes in extracellular traps," The Journal of Experimental Medicine, vol. 204, no. 4, pp. 793-804, 2007.

[5] A. Azzurri, O. Y. Sow, A. Amedei et al., "IFN- $\gamma$-inducible protein 10 and pentraxin 3 plasma levels are tools for monitoring inflammation and disease activity in Mycobacterium tuberculosis infection," Microbes and Infection, vol. 7, no. 1, pp. 1-8, 2005.

[6] M. Üstündaǧ, M. Orak, C. Güloǧlu, M. B. Sayhan, Ö. Alyan, and E. Kale, "Comparative diagnostic accuracy of serum levels of neutrophil activating peptide- 2 and pentraxin- 3 versus troponin-I in acute coronary syndrome," Anadolu Kardiyoloji Dergisi, vol. 11, no. 7, pp. 588-594, 2011.

[7] A. Parlak, A. Iyisoy, U. Aydogan, E. Cakir, and K. Saglam, "The effect of valsartan and nebivolol treatment on ADMA and pentraxin-3 levels in hypertensive patients," Medical Hypotheses, vol. 79, no. 3, pp. 294-298, 2012.
[8] H. Argani, A. Ghorbanihaghjo, G. Panahi, N. Rashtchizadeh, J. Safa, and S. M. Meimand, "Serum fetuin-A and pentraxin3 in hemodialysis and renal transplant patients," Clinical Biochemistry, vol. 45, no. 10-11, pp. 775-779, 2012.

[9] A. Aydogdu, I. Tasci, S. Tapan et al., "High plasma level of long Pentraxin 3 is associated with insulin resistance in women with polycystic ovary syndrome," Gynecological Endocrinology, vol. 28, no. 9, pp. 722-725, 2012.

[10] J. D. S. Gullo, M. M. Bertotti, C. C. P. Silva et al., "Hospital mortality of patients with severe traumatic brain injury is associated with serum PTX3 levels," Neurocritical Care, vol. 14, no. 2, pp. 194-199, 2011.

[11] M. Locatelli, S. Ferrero, F. M. Boneschi et al., "The long pentraxin PTX3 as a correlate of cancer-related inflammation and prognosis of malignancy in gliomas," Journal of Neuroimmunology, vol. 260, no. 1-2, pp. 99-106, 2013.

[12] E. P. Diamandis, L. Goodglick, C. Planque, and M. D. Thornquist, "Pentraxin-3 is a novel biomarker of lung carcinoma," Clinical Cancer Research, vol. 17, no. 8, pp. 2395-2399, 2011.

[13] A. T. Mairuhu, G. Peri, T. E. Setiati et al., "Elevated plasma levels of the long pentraxin, pentraxin 3, in severe dengue virus infections," Journal of Medical Virology, vol. 76, no. 4, pp. 547$552,2005$.

[14] J. F. P. Wagenaar, M. G. A. Goris, M. H. Gasem et al., "Long pentraxin PTX3 is associated with mortality and disease severity in severe Leptospirosis," Journal of Infection, vol. 58, no. 6, pp. 425432, 2009.

[15] B. Muller, G. Peri, A. Doni et al., "Circulating levels of the long pentraxin PTX3 correlate with severity of infection in critically ill patients," Critical Care Medicine, vol. 29, no. 7, pp. 1404-1407, 2001.

[16] P. M. Bossuyt, J. B. Reitsma, D. E. Bruns et al., "Towards complete and accurate reporting of studies of diagnostic accuracy: the STARD initiative," Clinical Chemistry, vol. 49, no. 1, pp. 1-6, 2003.

[17] P. M. Bossuyt, J. B. Reitsma, D. E. Bruns et al., "The STARD statement for reporting studies of diagnostic accuracy: explanation and elaboration," Clinical Chemistry, vol. 49, no. 1, pp. 7-18, 2003.

[18] T. Mauri, A. Coppadoro, G. Bellani et al., "Pentraxin 3 in acute respiratory distress syndrome: an early marker of severity," Critical Care Medicine, vol. 36, no. 8, pp. 2302-2308, 2008.

[19] T. Sprong, G. Peri, C. Neeleman et al., "Pentraxin 3 and Creactive protein in severe meningococcal disease," Shock, vol. 31, no. 1, pp. 28-32, 2009.

[20] T. Mauri, G. Bellani, N. Patroniti et al., "Persisting high levels of plasma pentraxin 3 over the first days after severe sepsis and septic shock onset are associated with mortality," Intensive Care Medicine, vol. 36, no. 4, pp. 621-629, 2010.

[21] M. D. de Kruif, M. Limper, K. Sierhuis et al., "PTX3 predicts severe disease in febrile patients at the emergency department," Journal of Infection, vol. 60, no. 2, pp. 122-127, 2010.

[22] R. Huttunen, M. Hurme, J. Aittoniemi et al., "High plasma level of long pentraxin 3 (PTX3) is associated with fatal disease in bacteremic patients: a prospective cohort study," PLOS ONE, vol. 6, no. 3, Article ID e17653, 2011.

[23] M. Vänskä, I. Koivula, S. Hämäläinen et al., "High pentraxin 3 level predicts septic shock and bacteremia at the onset of febrile neutropenia after intensive chemotherapy of hematologic patients," Haematologica, vol. 96, no. 9, pp. 1385-1389, 2011. 
[24] S. Bastrup-Birk, M.-O. Skjoedt, L. Munthe-Fog, J. J. Strom, Y. J. Ma, and P. Garred, "Pentraxin-3 serum levels are associated with disease severity and mortality in patients with systemic inflammatory response syndrome," PLOS ONE, vol. 8, no. 9, Article ID e73119, 2013.

[25] R. Uusitalo-Seppälä, R. Huttunen, J. Aittoniemi et al., "Pentraxin 3 (PTX3) is associated with severe sepsis and fatal disease in emergency room patients with suspected infection: a prospective Cohort study," PLOS ONE, vol. 8, no. 1, Article ID e53661, 2013.

[26] Q. Lin, F. Fu, L. Shen, and B. Zhu, "Pentraxin 3 in the assessment of ventilator-associated pneumonia: an early marker of severity," Heart and Lung: Journal of Acute and Critical Care, vol. 42, no. 2, pp. 139-145, 2013.

[27] S.-J. Kao, H.-W. Yang, S.-M. Tsao et al., "Plasma long pentraxin 3 (PTX3) concentration is a novel marker of disease activity in patients with community-acquired pneumonia," Clinical Chemistry and Laboratory Medicine, vol. 51, no. 4, pp. 907-913, 2013.

[28] C. Brun-Buisson, "The epidemiology of the systemic inflammatory response," Intensive Care Medicine, vol. 26, supplement 1, pp. S64-S74, 2000.

[29] G. S. Martin, "Sepsis, severe sepsis and septic shock: changes in incidence, pathogens and outcomes," Expert Review of AntiInfective Therapy, vol. 10, no. 6, pp. 701-706, 2012.

[30] D. C. Angus, W. T. Linde-Zwirble, J. Lidicker, G. Clermont, J. Carcillo, and M. R. Pinsky, "Epidemiology of severe sepsis in the United States: analysis of incidence, outcome, and associated costs of care," Critical Care Medicine, vol. 29, no. 7, pp. 1303-1310, 2001.

[31] J. D. Faix, "Biomarkers of sepsis," Critical Reviews in Clinical Laboratory Sciences, vol. 50, no. 1, pp. 23-36, 2013.

[32] M. Christ-Crain and B. Müller, "Biomarkers in respiratory tract infections: diagnostic guides to antibiotic prescription, prognostic markers and mediators," European Respiratory Journal, vol. 30, no. 3, pp. 556-573, 2007.

[33] P. Kopterides and I. Tsangaris, "Procalcitonin and sepsis: recent data on diagnostic utility prognostic potential and therapeutic implications in critically ill patients," Minerva Anestesiologica, vol. 78, no. 7, pp. 823-835, 2012.

[34] S. W. Standage and H. R. Wong, "Biomarkers for pediatric sepsis and septic shock," Expert Review of Anti-Infective Therapy, vol. 9, no. 1, pp. 71-79, 2011.

[35] K. L. Becker, R. Snider, and E. S. Nylen, "Procalcitonin assay in systemic inflammation, infection, and sepsis: clinical utility and limitations," Critical Care Medicine, vol. 36, no. 3, pp. 941-952, 2008.

[36] P. Schuetz, M. Christ-Crain, and B. Müller, "Procalcitonin and other biomarkers to improve assessment and antibiotic stewardship in infections-hope for hype?" Swiss Medical Weekly, vol. 139, no. 23-24, pp. 318-326, 2009.

[37] F. Breviario, E. M. D’Aniello, J. Golay et al., "Interleukin-1inducible genes in endothelial cells. Cloning of a new gene related to C-reactive protein and serum amyloid P component," The Journal of Biological Chemistry, vol. 267, no. 31, pp. 2219022197, 1992.

[38] G. W. Lee, T. H. Lee, and J. Vilček, "TSG-14, a tumor necrosis factor- and IL-1-inducible protein, is a novel member of the pentaxin family of acute phase proteins," Journal of Immunology, vol. 150, no. 5, pp. 1804-1812, 1993.

[39] A. Basile, A. Sica, E. D’Aniello et al., "Characterization of the promoter for the human long pentraxin PTX3: role of NF- $\kappa$ B in tumor necrosis factor- $\alpha$ and interleukin- $\beta$ regulation," Journal of Biological Chemistry, vol. 272, no. 13, pp. 8172-8178, 1997.

[40] B. Bottazzi, V. Vouret-Craviari, A. Bastone et al., "Multimer formation and ligand recognition by the long pentraxin PTX3: similarities and differences with the short pentraxins C-reactive protein and serum amyloid P component," The Journal of Biological Chemistry, vol. 272, no. 52, pp. 32817-32823, 1997.

[41] M. Introna, V. Vidal Alles, M. Castellano et al., "Cloning of mouse ptx3, a new member of the pentraxin gene family expressed at extrahepatic sites," Blood, vol. 87, no. 5, pp. 1862$1872,1996$.

[42] A. Doni, G. Mantovani, C. Porta et al., "Cell-specific regulation of PTX3 by glucocorticoid hormones in hematopoietic and nonhematopoietic cells," The Journal of Biological Chemistry, vol. 283, no. 44, pp. 29983-29992, 2008.

[43] C. Garlanda, B. Bottazzi, A. Bastone, and A. Mantovani, "Pentraxins at the crossroads between innate immunity, inflammation, matrix deposition, and female fertility," Annual Review of Immunology, vol. 23, no. 4, pp. 337-366, 2005.

[44] B. Bottazzi, C. Garlanda, A. Cotena et al., "The long pentraxin PTX3 as a prototypic humoral pattern recognition receptor: interplay with cellular innate immunity," Immunological Reviews, vol. 227, no. 1, pp. 9-18, 2009.

[45] E. Litton, K. M. Ho, and S. A. R. Webb, "Comparison of physician prediction with 2 prognostic scoring systems in predicting 2 -year mortality after intensive care admission: a linked-data cohort study," Journal of Critical Care, vol. 27, no. 4, pp. 423.e9423.e15, 2012.

[46] J.-R. Le Gall, S. Lemeshow, and F. Saulnier, "A new simplified acute physiology score (SAPS II) based on a European/North American multicenter study," The Journal of the American Medical Association, vol. 270, no. 24, pp. 2957-2963, 1993.

[47] M. Mirsaeidi, P. Peyrani, and J. A. Ramirez, "Predicting mortality in patients with ventilator-associated pneumonia: the APACHE II score versus the new IBMP-10 score," Clinical Infectious Diseases, vol. 49, no. 1, pp. 72-77, 2009.

[48] A. Kumar, D. Roberts, K. E. Wood et al., "Duration of hypotension before initiation of effective antimicrobial therapy is the critical determinant of survival in human septic shock," Critical Care Medicine, vol. 34, no. 6, pp. 1589-1596, 2006.

[49] J. L. Moran, P. Bristow, P. J. Solomon, C. George, and G. K. Hart, "Mortality and length-of-stay outcomes, 1993-2003, in the binational Australian and New Zealand intensive care adult patient database," Critical Care Medicine, vol. 36, no. 1, pp. 4661, 2008.

[50] W. Ge, H.-L. Wang, and R.-P. Sun, "Pentraxin 3 as a novel early biomarker for the prediction of Henoch-Schönlein purpura nephritis in children," European Journal of Pediatrics, vol. 173, no. 2, pp. 213-218, 2014.

[51] S. Goodison, M. Chang, Y. Dai, V. Urquidi, and C. J. Rosser, "A multi-analyte assay for the non-invasive detection of bladder cancer," PLoS ONE, vol. 7, no. 10, Article ID e47469, 2012.

[52] E. R. Zanier, G. Brandi, G. Peri et al., "Cerebrospinal fluid pentraxin 3 early after subarachnoid hemorrhage is associated with vasospasm," Intensive Care Medicine, vol. 37, no. 2, pp. 302309, 2011

[53] C. D. Yeo, J. W. Kim, M. R. Cho et al., "Pleural fluid pentraxin-3 for the differential diagnosis of pleural effusions," Tuberculosis and Respiratory Diseases, vol. 75, no. 3, pp. 244-249, 2013.

[54] S. Ozsu, Y. Abul, A. Mentese et al., "Pentraxin-3: a novel biomarker for discriminating parapneumonic from other exudative effusions," Respirology, vol. 18, no. 4, pp. 657-662, 2013. 
[55] L. Cruciani, R. Romero, E. Vaisbuch et al., "Pentraxin 3 in amniotic fluid: a novel association with intra-amniotic infection and inflammation," Journal of Perinatal Medicine, vol. 38, no. 2, pp. 161-171, 2010.

[56] M. M. Luchetti, G. Piccinini, A. Mantovani et al., "Expression and production of the long pentraxin PTX3 in rheumatoid arthritis (RA)," Clinical \& Experimental Immunology, vol. 119, no. 1, pp. 196-202, 2000.

[57] S. Padeh, N. Farzam, G. Chayen, M. Gerstein, and Y. Berkun, "Pentraxin 3 is a marker of early joint inflammation in patients with juvenile idiopathic arthritis," Immunologic Research, vol. 56, no. 2-3, pp. 444-450, 2013. 


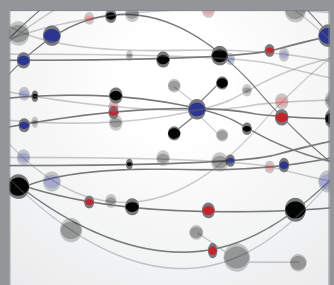

The Scientific World Journal
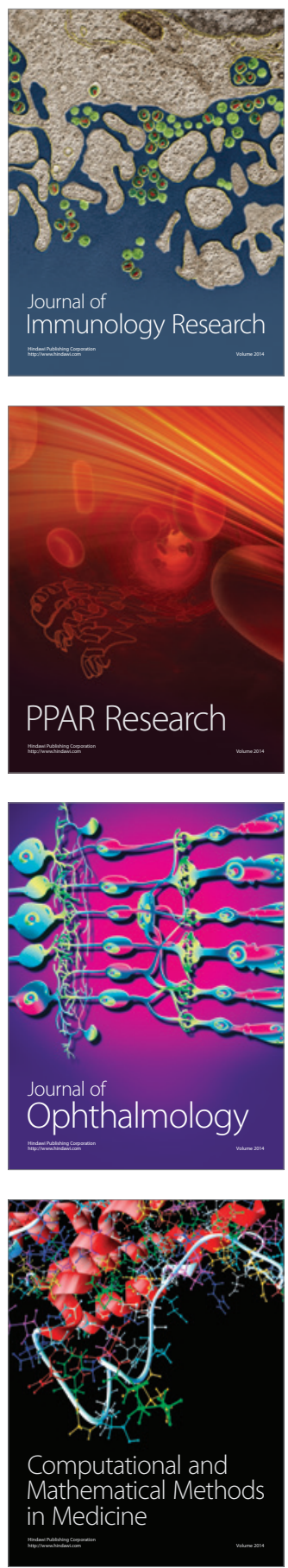

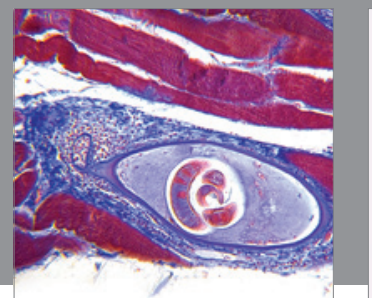

Gastroenterology

Research and Practice
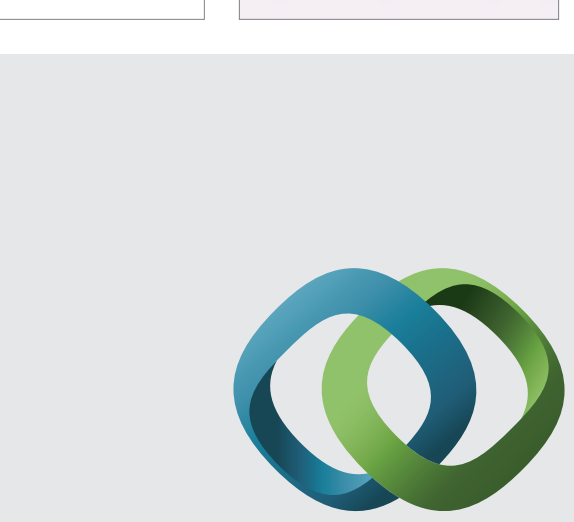

\section{Hindawi}

Submit your manuscripts at

http://www.hindawi.com
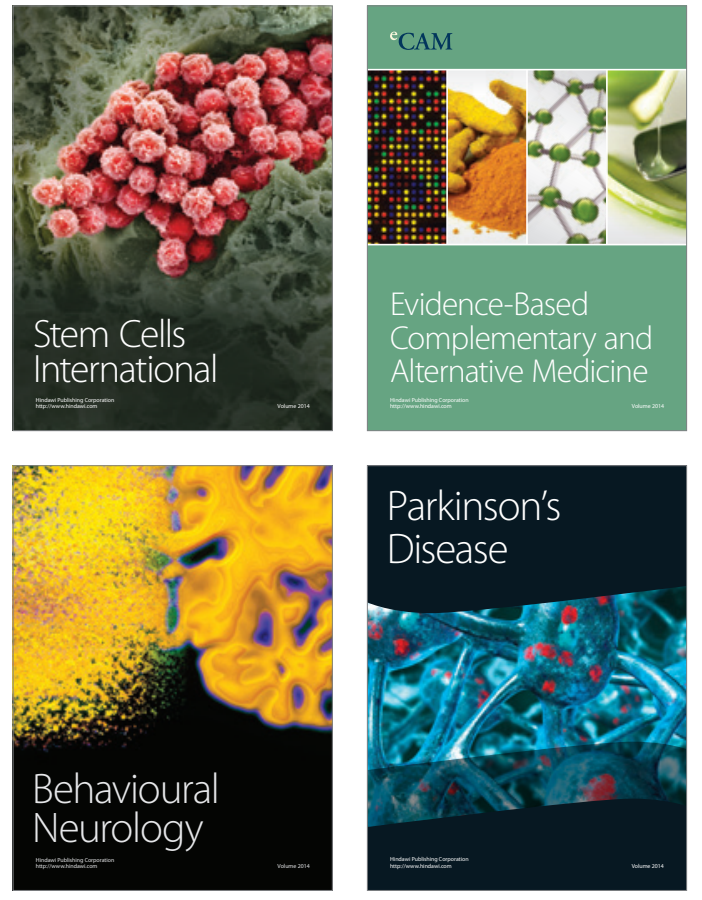
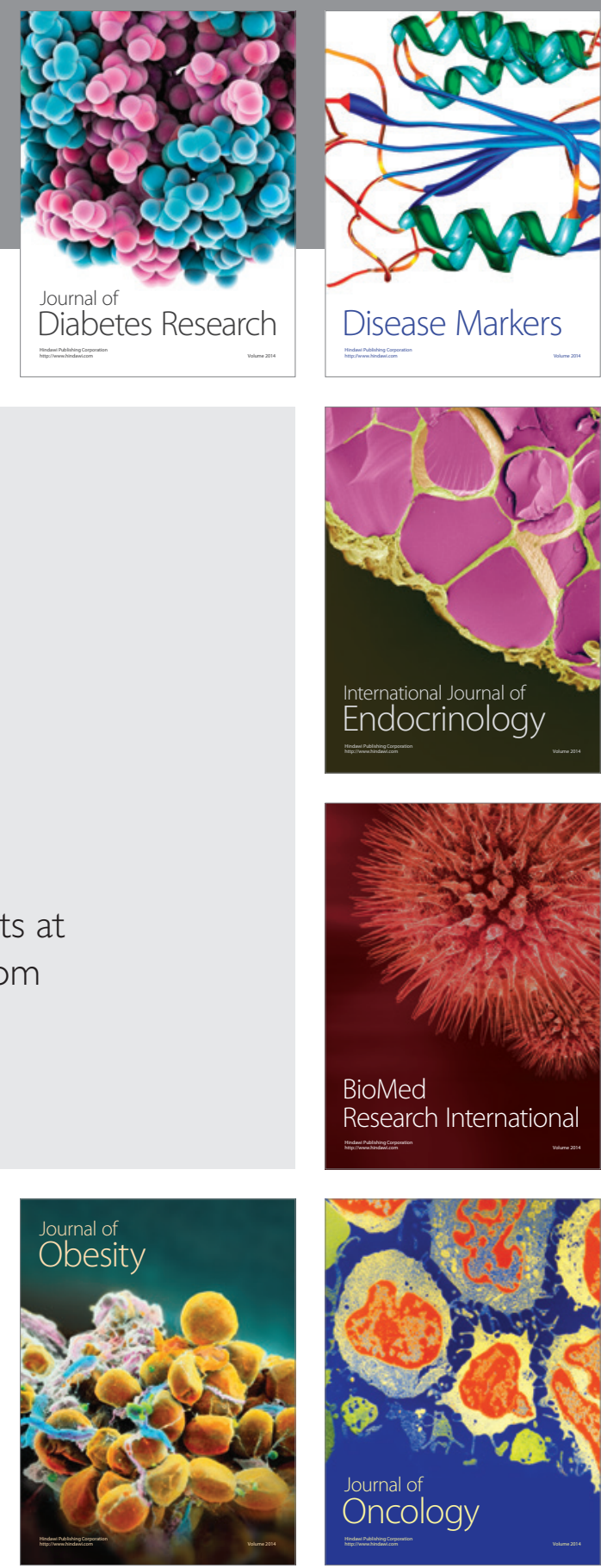

Disease Markers
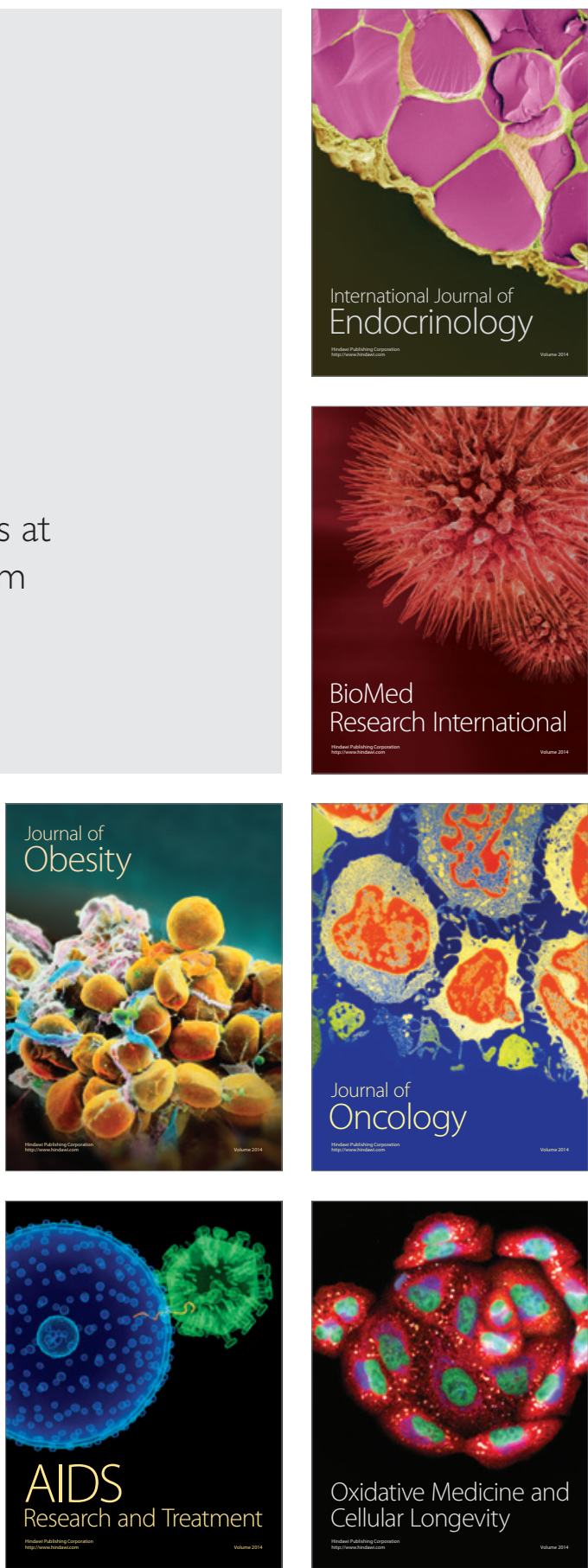